\title{
Climate Change and Developing-Country Cities: Implications For Environmental Health and Equity
}

\author{
Diarmid Campbell-Lendrum and Carlos Corvalán
}

\begin{abstract}
Climate change is an emerging threat to global public health. It is also highly inequitable, as the greatest risks are to the poorest populations, who have contributed least to greenhouse gas (GHG) emissions. The rapid economic development and the concurrent urbanization of poorer countries mean that developingcountry cities will be both vulnerable to health hazards from climate change and, simultaneously, an increasing contributor to the problem. We review the specific health vulnerabilities of urban populations in developing countries and highlight the range of large direct health effects of energy policies that are concentrated in urban areas. Common vulnerability factors include coastal location, exposure to the urban heatisland effect, high levels of outdoor and indoor air pollution, high population density, and poor sanitation. There are clear opportunities for simultaneously improving health and cutting GHG emissions most obviously through policies related to transport systems, urban planning, building regulations and household energy supply. These influence some of the largest current global health burdens, including approximately 800,000 annual deaths from ambient urban air pollution, 1.2 million from road-traffic accidents, 1.9 million from physical inactivity, and 1.5 million per year from indoor air pollution. GHG emissions and health protection in developing-country cities are likely to become increasingly prominent in policy development. There is a need for a more active input from the health sector to ensure that development and health policies contribute to a preventive approach to local and global environmental sustainability, urban population health, and health equity.
\end{abstract}

KEYWORDS Climate change, Cities, Energy, Equity, Health, Transport.

Abbreviations: IPCC - Intergovernmental Panel on Climate Change; GHG-greenhouse gas; WHO - World Health Organization

\section{INTRODUCTION}

Whoever wishes to investigate medicine properly, should proceed thus: in the first place to consider the seasons of the year, and what effects each of them produces for they are not at all alike, but differ much from themselves in regard to their changes. Then the winds, the hot and the cold, especially such as are common to all countries, and then such as are peculiar to each locality. In the same manner, when one comes into a city

Campbell-Lendrum and Corvalán are with the Department of Public Health and Environment, World Health Organization, Geneva 27, Switzerland.

Correspondence: Diarmid Campbell-Lendrum, Department of Public Health and Environment, World Health Organization, 20, Avenue Appia, 1211, Geneva 27, Switzerland. (E-mail: campbelllendrumd@ who.int) 
to which he is a stranger, he ought to consider its situation, how it lies as to the winds and the rising of the sun; for its influence is not the same whether it lies to the north or the south, to the rising or to the setting sun.-Hippocrates ("Airs, waters, and places." Approx. 350 вC)

Emissions of the greenhouse gases (GHGs) which cause climate change are currently determined mainly by consumption patterns in cities of the developed world. The most recent completed report of the Intergovernmental Panel on Climate Change (IPCC) ${ }^{1}$ reported that in 1990, buildings were responsible for approximately $20 \%$ of global emissions. Transport was estimated to contribute to $13 \%$ of GHG emissions, with the total contribution expected to more than double by 2020 . In addition to the direct effects on the environment, the increasing requirements of urban populations also cause "displaced" effects on ecosystem services in other locations. For example, the agriculture sector increasingly produces and transports food and fiber for urban populations in rich countries. Agricultural production and waste contributed $18 \%$ of GHG emissions in 1990, with total emissions estimated to increase by about $50 \%$ by $2020,{ }^{1}$ and can degrade land and water resources. ${ }^{2}$ The forthcoming fourth assessment report of the IPCC, due for publication throughout 2007, is expected to confirm the broad pattern and approximate magnitude of these trends and their climatic impacts.

Currently, populations of low- and middle-income countries have a much lower impact on the global environment. Per capita emissions of GHGs in the USA, for example, are over seven times higher than in China and 19 times higher than in Africa. ${ }^{3}$ This underscores the urgency of actions to reduce GHG emissions in all developed countries. However, while the impact of each individual citizen in developing countries will remain lower than in developed country counterparts for the foreseeable future, these populations are simultaneously urbanizing, growing, and increasing consumption rates. In the clearest example, China is poised to overtake the USA as the largest single emitter of carbon dioxide before $2010 .^{3}$ Decisions made in developing-country cities in the next few decades will therefore be among the most important determinants of new and future local and global environmental stresses. ${ }^{4}$

These trends have two major implications for public health. First, they require a reconsideration of policies to protect health from climate-related threats in cities of the developing world. ${ }^{5}$ Secondly, there is likely to be an increasing attention paid to policies that can reduce GHG emissions, many of which also have major direct health consequences. Decision makers would therefore benefit from assessments that can assist them to select development policies that can bring synergies or optimize trade-offs between protecting the local and global environment while also bringing health gains. ${ }^{2}$

\section{URBAN HEALTH VULNERABILITIES TO GLOBAL CLIMATE CHANGE}

The IPCC has assessed that the global mean temperature is likely to rise by 1.4$5.8^{\circ} \mathrm{C}$ between 1990 and 2100 with associated changes in the hydrological cycle. These will cause a range of health impacts. ${ }^{6}$ A World Health Organization (WHO) quantitative assessment, taking into account only a subset of the possible health impacts, concluded that the effects of the climate change that have occurred since the mid-1970s may have caused a net increase of over 150,000 deaths in 2000. It 
also concluded that these impacts are likely to increase in the future. ${ }^{7}$ This has an important equity dimension; the largest health risks are to children in the poorest communities, who have contributed least to GHG emissions. ${ }^{8}$

The rapid urbanization of the global population calls for a consideration of how these trends apply to developing-country cities. Close to $50 \%$ of the world population now lives in urban areas compared with only $15 \%$ in $1900 .{ }^{9}$ City living should reduce vulnerability in several important respects, including lower rates of diseases such as malaria, and often higher individual incomes and better access to health services. ${ }^{4}$ However, urban populations, particularly the poor, also share some important vulnerabilities. It is estimated that over 900 million people, onethird of the global urban population, and more than $70 \%$ of urban developingcountry populations, now live in slum-like conditions. These are characterized by low incomes, poor housing and provision of basic services, and no effective regulation of pollution or ecosystem degradation. This number is projected to increase to roughly 2 billion by $2020 .{ }^{9}$ Health concerns for this group will therefore become increasingly important and include:

\section{Heat Waves}

Heat waves in cities are exacerbated by the urban "heat-island" effect. These result from lowered evaporative cooling, increased heat storage and sensible heat flux caused by lowered vegetation cover, increased impervious cover and complex surfaces, and possibly from heat trapping by elevated levels of locally produced $\mathrm{CO}_{2} \cdot{ }^{10}$ Individual cities show a large heat-island effect, measuring up to $5-11^{\circ} \mathrm{C}$ warmer than the surrounding rural areas. ${ }^{11}$ Wider urban sprawl further exacerbates the effect ${ }^{12}$ : in southeast China, such land-use patterns have been estimated to account for $\sim 0.05^{\circ} \mathrm{C}$ of regional warming per decade since $1978 .^{13}$

Heat waves can cause dramatic impacts on urban health. The most striking example was the extended period of record high temperatures ${ }^{14}$ experienced in Europe in summer 2003, which was made significantly more likely by humaninduced climate change. ${ }^{15}$ This caused excess mortality of over 35,000 people within a 1 - to 2 -week period in early August. ${ }^{16}$ Global trends toward higher and increasingly variable temperatures are expected to further increase the frequency of heat waves. ${ }^{1}$ While the effects in temperate developed regions may be partly compensated by lower winter mortality and adaptation, ${ }_{18}^{17}$ poor populations in tropical developing cities do not show such compensation. ${ }^{18}$

\section{Floods and Storms}

Many of the world's largest and fastest growing cities are located on the coast, and therefore vulnerable to sea-level rise. They are also exposed to the more frequent severe windstorms and floods that some studies are already linking to past ${ }^{19,20}$ and future climate change. ${ }^{21,22}$ In addition, construction patterns in many developing cities have resulted in a combination of degradation of natural protection (e.g., through deforestation and building on floodplains), poor-quality housing construction on exposed slopes, and extensive ground coverage of concrete without adequate drainage. Heavy rains therefore often result in intense, and sometimes lethal, flash floods, such as those that occurred in and around Caracas, Venezuela in 1999 and Mumbai, India in July 2005. Economic development offers the opportunity for improved protection through improvements in housing quality and flood protection. However, the extent of protection depends both on development decisions (e.g., whether to build on floodplains ${ }^{23}$ ) and on social 
cohesion and the adequacy of response plans. Poorer populations are often penalized in each of these respects. Early evidence from Hurricane Katrina in New Orleans, USA in August 2005 suggests that even in the richest countries, social inequities and poor disaster response can worsen health impacts. ${ }^{24}$

\section{Communicable Diseases}

Many waterborne and vectorborne infectious diseases are strongly influenced by climate conditions, and several are common within cities. The clearest example is dengue, the most important vectorborne virus globally. Dengue transmission has increased dramatically in tropical developing regions in the past few decades due to the weakening of vertical control programs in many regions, coupled with rapid unplanned urbanization, producing breeding sites for Aedes mosquitoes, and high human population densities, supplying a large pool of susceptible individuals. ${ }^{25}$ Increasing travel has helped to spread the four different serotypes of dengue around the world, heightening exposure to multiple strains, which in turn increases the severity of clinical disease. In addition, the distributions of Aedes and dengue are favored by high absolute humidity, which increases with high temperatures and rainfall. ${ }^{26,27}$ Climate change is therefore projected to cause important increases in dengue endemic areas both at the global level ${ }^{28}$ and within certain developing regions, including China. ${ }^{29}$ Again, socioeconomic development, improving housing, ${ }^{30}$ and appropriate control interventions ${ }^{31}$ can help to counter these trends but may not offer complete protection particularly if control programs are not sustained over time. Singapore is one of the richest countries in the world; yet, dengue is reemerging there, ${ }^{32}$ with almost half of local adults surveyed showing evidence of previous infection. ${ }^{33}$ More speculatively, global environmental changes may favor the emergence of new infectious diseases, ${ }^{34,35}$ which may spread faster within and between cities due to travel links and higher rates of person-to-person contact.

\section{Air Pollution}

Levels of many pollutants, such as ozone, are affected by atmospheric conditions and tend to be higher on warmer days. Epidemiological evidence from developingcountry cities is weak, but inferences from developed countries suggest significant risks associated with increasing temperatures. Studies of 15 cities in the southeastern USA have shown that under one of the more severe scenarios of future climate change (IPCC SRES A2 scenario), by the 2050s, climate change can be expected to raise the average number of days in which the 8 -h ozone standard is exceeded by $60 \%$ and cause ozone-related deaths to increase by $\sim 4.5 \% .^{36,37}$ This is likely to be reflected to some degree in urban populations across the world and represents only one of a wide range of negative effects of climate change on health and on other ecosystem services underpinning human well-being. ${ }^{2,8}$

\section{IMPROVING URBAN HEALTH WHILE PROTECTING THE GLOBAL CLIMATE}

While climatic threats to urban health are important, there are also major opportunities for improving health status, including health equity, while protecting the global climate. Comprehensive assessments have recently demonstrated the magnitude of the global health burdens connected with energy and transport policies. ${ }^{38}$ The most obvious is urban ambient air pollution, which causes 
approximately 800,000 deaths per year worldwide. ${ }^{39}$ The few studies in this field suggest that implementing currently available technologies to reduce fossil-fuel use could bring major health benefits: approximately 64,000 fewer deaths between 2000 and 2020 in Mexico City, Santiago, São Paulo, and New York alone ${ }^{40,41}$ and significantly reduced mortality in China. ${ }^{42}$ However, studies also suggest the need for careful assessment; poorly designed mitigation policies (e.g., taxing $\mathrm{CO}_{2}$ emissions without simultaneously tightening particulate air pollution controls) may lead to reduced health benefits or net harm. ${ }^{43}$

Newer studies have begun to highlight synergies with efforts to address other hazards, such as indoor air pollution from solid-fuel use ${ }^{44,45}$ that kills over 1.5 million each year and is still widespread among the poorest populations in developing-country cities. ${ }^{46}$ In Africa, for example, large-scale transitions to more efficient fossil fuels could bring both a small (1-10\%) reduction in GHG emissions and a large $(13-38 \%)$ reduction in the 9.8 million excess deaths that are expected from the present to $2030 .{ }^{45}$ This indicated that both the environment and human health would be enhanced by promoting clean burning fossil fuels, such as liquefied petroleum gas, for domestic use in poorer countries, while both reducing fossil-fuel use and developing cheaper renewable technologies in richer nations. ${ }^{47}$

There is scope for further synergies. The transport sector is expected to more than double its contribution to GHG emissions over the period of 1990-2020. ${ }^{1}$ Apart from contributing to urban air pollution, road-traffic accidents kill 1.2 million people per year. ${ }^{48}$ Transport systems and other aspects of urban design further influence levels of physical inactivity, ${ }^{49}$ which cause approximately 1.9 million deaths per year. ${ }^{39}$ Taken together, this burden of disease is of similar size to that caused by unsafe water, sanitation, and hygiene (1.7 million annual global deaths), unsafe sex (2.9 million), or tobacco use (4.9 million). ${ }^{39}$

"Healthy urbanization" should therefore consider the wide range of technological and planning options that could all supply mobility needs to increasingly wealthy populations but have very different implications for GHG emissions and for health. For example, the percentage of people walking or cycling to work varies from $0.3 \%$ in Atlanta to $22 \%$ in Tokyo and to $32 \%$ in Copenhagen. Values in developing countries are equally variable, from $2 \%$ in Brasilia to $30 \%$ in Santiago. The percentage of urban trips by motorized private transport as opposed to public transport, walking, or cycling (which is typically three to five times more energy efficient) ranges from $89 \%$ in the USA to $50 \%$ in western Europe, $42 \%$ in highincome Asia, and $16 \%$ in China. ${ }^{50,51}$

Similarly, the range of direct interactions between urban housing, climate change, and health goes beyond indoor air pollution. Urban planning affects energy consumption and associated emissions through the building and transport sectors, as well as the extent of the urban heat-island effect. Design and insulation of houses determine the energy consumption and the risk of mortality in both hot and cold extremes. ${ }^{52}$ This offers a scope for actions at the individual level (e.g., investment in insulation) or at the municipal or national level (e.g., defining minimum standards for insulation in new buildings), which have the capacity to simultaneously enhance health, reduce consumption, and provide economic benefits.

\section{DISCUSSION}

The interactions described above provide opportunities for mutually reinforcing local and global environmental sustainability and population health. 
A greater consideration of health evidence would make a major contribution to policy making on climate change, as it has done for other environmental issues. A range of assessments have shown that health impacts are often the largest single contributor to the costs of environmental damages (e.g., two-thirds of the monetarized costs of degradation in $\mathrm{Egypt}^{53}$ ) and can dominate cost-benefit analyses for environmental protection policies (e.g., the estimated 42:1 benefit/cost ratio for the U.S. Clean Air $\mathrm{Act}^{54}$ ). The sheer size of the direct and indirect health consequences of energy policies suggests that greater consideration of health evidence could strengthen the case for climate policies and improve their design.

As a complement, climate change has brought additional attention to urban planning and technological choices in the energy and transport sectors, providing an opportunity for greater engagement by the health sector. Planners in developing countries also have the benefit of an emerging understanding of how alternative systems in developed countries have impacted on health and the environment (e.g., see the studies of Dora and Phillips ${ }^{55}$ and Frumkin, ${ }^{12,56}$ for reviews). Advances in assessment methods are needed, however, to make better linkages between environmental considerations and urban health and health equity. The few integrated assessments carried out so far have assessed benefits only from reduced air pollution and risk falling into the trap of producing "complete cost-incomplete benefit assessments," biasing toward policy inaction or narrow technical solutions that are more easily quantified (e.g., promoting cleaner fuels rather than promoting active transport). In the meantime, qualitative methods can help to represent the full range of health consequences as well as local attitudes and perspectives. ${ }^{57}$

Health and ecological sustainability would also be enhanced by more active promotion of the "Healthy Cities" concept, supporting not just an absence of disease but a physical and social environment that enhances all aspects of physical and mental well-being. This should include an explicit focus on health equity. Health equity would be enhanced by (1) reducing the current emissions of GHGs from the richest sections of society (i.e., avoiding loading health risks onto the poorest populations), (2) international support for adaptation measures to protect the health of the most vulnerable, and (3) favoring GHG reduction policies that maximize health co-benefits for the poor (e.g., enhancing opportunities for public and active transport and improving energy efficiency and insulation in poor housing).

There are encouraging signals that urban populations of developing countries will be active partners in positive change. Health-driven environmental concerns are today most keenly felt among urban dwellers in low-income countries. For example, $24 \%$ of Chinese respondents believe that the environment and climate change are the most important problem facing the world compared to less than $2 \%$ in the USA. ${ }^{58}$ Cities are often cosmopolitan and built around trade, increasing awareness of globalization and interconnectivity. Many cities now work together directly, both nationally and internationally, to address sustainability issues. ${ }^{59}$ Such partnerships are likely to grow as the common interests of urban populations in protecting the local and global environment become more apparent.

\section{CONCLUSIONS}

Urban populations in developing countries are both vulnerable and are increasingly contributors to climatic threats to health. Specific health vulnerabilities range from heat waves and air-pollution impacts to sea-level rise and storms in coastal cities 
and to emerging infectious diseases. At the same time, these cities are growing consumers of resources and contributors to GHG emissions. If rapid urbanization focuses only on short-term economic development rather than sustainability, this is likely to lead to development paths that exacerbate global climate change with a wide range of, largely negative, implications for global health and health equity. The interaction between energy policies, climate change, and health creates both a need and an opportunity for the public-health community to further develop its methods for assessing complex and diffuse risks and to engage more actively in development decisions. This should help to ensure that decisions taken in developing-country cities support a preventive environmental health agenda and serve the ultimate goal of promoting human health and well-being. ${ }^{60}$

\section{ACKNOWLEDGMENTS}

This paper was developed from a presentation made at the "Healthy Cities" conference in Shanghai, China, September 2005. The views expressed in this article are those of the authors and do not necessarily reflect the position of the World Health Organization.

\section{REFERENCES}

1. IPCC. Climate Change 2001: Synthesis Report. Cambridge: WMO/UNEP, 2001.

2. Millennium Ecosystem Assessment. Ecosystems and Human Well Being: Health Synthesis. Geneva: World Health Organization, 2005.

3. IEA. World Energy Outlook. Vienna: International Energy Agency, 2006.

4. McGranahan G, Marcotullio P, Balk D, et al. Urban Systems. Ecosystems and Human Well-Being: Current State and Trends: Findings of the Condition and Trends Working Group. Washington: Island Press; 2005:795-825.

5. McMichael AJ. The urban environment and health in a world of increasing globalization: issues for developing countries. Bull World Health Organ. 2000;78(9):1117-1126.

6. McMichael AJ, Githeko A. Human Health. In: McCathy JJ, Canziani OF, Leary NA, Dokken DJ, White KS, eds. Climate Change 2001: Impacts, Adaptation and Vulnerability. Cambridge: Cambridge University Press; 2001:451-485.

7. McMichael A, Campbell-Lendrum D, Kovats R, et al. Climate Change. In: Ezzati M, Lopez A, Rodgers A, Murray C, eds. Comparative Quantification of Health Risks: Global and Regional Burden of Disease due to Selected Major Risk Factors. Geneva: World Health Organization, 2004.

8. Patz JA, Campbell-Lendrum D, Holloway T, Foley JA. Impact of regional climate change on human health. Nature. 2005;438(7066):310-317.

9. Wall DH, Rabbinge R, Gallopin G, et al., eds. Implications for Achieving the Millennium Development Goals. Millennium Ecosystem Assessment: Ecosystems and Human Well-Being: Volume III-Policy Responses. Washington, D.C.: Island Press; 2005:549-584.

10. Idso CD, Idso SB, Balling RC. An intensive two-week study of an urban $\mathrm{CO}_{2}$ dome in Phoenix, Arizona, USA. Atmos Environ. 2001;35(6):995-1000.

11. Aniello C, Morgan K, Busbey A, Newland L. Mapping micro-urban heat islands using Landsat TM and a GIS. Comput Geosci. 1995;21(8):965-969.

12. Frumkin H. Urban sprawl and public health. Public Health Rep. 2002;117(3):201-217.

13. Zhou L, Dickinson RE, Tian Y, et al. Evidence for a significant urbanization effect on climate in China. Proc Natl Acad Sci U S A 2004;101(26):9540-9544.

14. Schar C, Vidale PL, Luthi D, et al. The role of increasing temperature variability in European summer heatwaves. Nature. 2004;427(6972):332-336. 
15. Stott PA, Stone DA, Allen MR. Human contribution to the European heatwave of 2003. Nature. 2004;432(7017):610-614.

16. Kosatsky T. The 2003 European heat waves. Euro Surveill. 2005;10(7).

17. Davis RE, Knappenberger PC, Novicoff WM, Michaels PJ. Decadal changes in summer mortality in U.S. cities. Int J Biometeorol. 2003;47(3):166-175.

18. Hajat S, Armstrong BG, Gouveia N, Wilkinson P. Mortality displacement of heat-related deaths: a comparison of Delhi, São Paulo, and London. Epidemiology. 2005;16(5):613-620.

19. Emanuel K. Increasing destructiveness of tropical cyclones over the past 30 years. Nature. 2005;436(7051):686-688.

20. Webster PJ, Holland GJ, Curry JA, Chang HR. Changes in tropical cyclone number, duration, and intensity in a warming environment. Science. 2005;309:1844-1846.

21. Knutson TR, Tuleya RE. Impact of CO2-induced warming on simulated hurricane intensity and precipitation: sensitivity to the choice of climate model and convective parameterization. J Climate. 2004;17(18):3477-3495.

22. Palmer TN, Ralsanen J. Quantifying the risk of extreme seasonal precipitation events in a changing climate. Nature. 2002;415(6871):512-514.

23. Pielke RA, Landsea C, Mayfield M, Laver J, Pasch R. Hurricanes and global warming. Bull Am Meteorol Soc. 2005;86(11):1571-1575.

24. Greenough PG, Kirsch TD. Hurricane Katrina. Public health response-assessing needs. $N$ Engl J Med. 2005;353(15):1544-1546.

25. Gubler DJ, Meltzer M. Impact of dengue/dengue hemorrhagic fever on the developing world. Adv Virus Res. 1999;53:35-70.

26. Nagao Y, Thavara U, Chitnumsup P, Tawatsin A, Chansang C, Campbell-Lendrum D. Climatic and social risk factors for Aedes infestation in rural Thailand. Trop Med Int Health. 2003;8(7):650-659.

27. Yi B, Zhang Z, Xu D, Xi Y. Relationship of dengue fever epidemic to Aedes density changed by climate factors in Guangdong Province [article in Chinese]. Wei Sheng Yan Jiu. 2003;32(2):152-154.

28. Hales S, de Wet N, Maindonald J, Woodward A. Potential effect of population and climate changes on global distribution of dengue fever: an empirical model. Lancet. 2002;360(9336):830-834.

29. Yu SX, Li ZQ, Teng WP, Cai J. Impact on the potential epidemic of dengue fever under warming winter in Hainan province [article in Chinese]. Zhonghua Liu Xing Bing Xue Za Zhi. 2005;26(1):25-28.

30. Reiter P, Lathrop S, Bunning M, et al. Texas lifestyle limits transmission of dengue virus. Emerg Infect Dis. 2003;9(1):86-89.

31. Kay B, Vu SN. New strategy against Aedes aegypti in Vietnam. Lancet. 2005;365(9459): 613-617.

32. Goh KT. Dengue-a re-emerging infectious disease in Singapore. Ann Acad Med Singapore. 1997;26(5):664-670.

33. Wilder-Smith A, Foo W, Earnest A, Sremulanathan S, Paton NI. Seroepidemiology of dengue in the adult population of Singapore. Trop Med Int Health. 2004;9(2):305-308.

34. Daszak P, Cunningham AA, Hyatt AD. Anthropogenic environmental change and the emergence of infectious diseases in wildlife. Acta Trop. 2001;78(2):103-116.

35. Harvell CD, Mitchell CE, Ward JR, et al. Climate warming and disease risks for terrestrial and marine biota. Science. 2002;296(5576):2158-2162.

36. Hogrefe C, Lynn B, Civerolo K, et al. Simulating changes in regional air pollution over the eastern United States due to changes in global and regional climate and emissions. $J$ Geophys Res. 2004;109(D22):2627-2638.

37. Knowlton K, Rosenthal JE, Hogrefe C, et al. Assessing ozone-related health impacts under a changing climate. Environ Health Perspect. 2004;112(15):1557-1563.

38. Ezzati M, Lopez A, Rodgers A, Murray C, eds. Comparative Quantification of Health Risks: Global and Regional Burden of Disease due to Selected Major Risk Factors. Geneva: World Health Organization, 2004. 
39. WHO. The World Health Report 2002. Geneva: WHO, 2002.

40. Cifuentes L, Borja-Aburto VH, Gouveia N, Thurston G, Davis DL. Assessing the health benefits of urban air pollution reductions associated with climate change mitigation (2000-2020): Santiago, São Paulo, Mexico City, and New York City. Environ Health Perspect. 2001;109(Suppl 3):419-425.

41. Cifuentes L, Borja-Aburto VH, Gouveia N, Thurston G, Davis DL. Climate change. Hidden health benefits of greenhouse gas mitigation. Science. 2001;293(5533):1257-1259.

42. Aunan K, Fang JH, Vennemo H, Oye K, Seip HM. Co-benefits of climate policy-lessons learned from a study in Shanxi, China. Energy Policy. 2004;32(4):567-581.

43. Mazzi EA, Dowlatabadi H. Air quality impacts of climate mitigation: UK policy and passenger vehicle choice. Environ Sci Technol. 2006;41(2):387-392.

44. Wang X, Smith K. Secondary benefits of greenhouse gas control: health impacts in China. Environ Sci Technol. 1999;33:3056-3061.

45. Bailis R, Ezzati M, Kammen DM. Mortality and greenhouse gas impacts of biomass and petroleum energy futures in Africa. Science. 2005;308(5718):98-103.

46. WHO. Fuel for Life: Household Energy and Health. Geneva: World Health Organization, 2006.

47. Smith KR. In praise of petroleum? Science. 2002;298(5600):1847.

48. WHO. The World Health Report 2004. Geneva: WHO, 2004.

49. Saelens BE, Sallis JF, Frank LD. Environmental correlates of walking and cycling: findings from the transportation, urban design, and planning literatures. Ann Behav Med. 2003;25(2):80-91.

50. Newman P, Kenworthy J. Sustainability and Cities: Overcoming Automobile Dependence. Washington DC: Island Press, 1999.

51. Kenworthy J. Transport Energy Use and Greenhouse Gases in Urban Passenger Transport Systems: A Study of 84 Global Cities. Proceedings of the International Third Conference of the Regional Government Network for Sustainable Development, Notre Dame University, Fremantle, Western Australia, 2003.

52. Thomson H, Pettigrew M, Morrison D. Housing Improvement and Health Gain: Summary and Systematic Review. Glasgow: MRC Social and Public Sciences Group, 2002.

53. Larsen B, Sarraf M, Pillet G. Cost Assessment of Environmental Degradation in Egypt. Washington, DC: World Bank/METAP, 2002.

54. USEPA. The Benefits and Costs of the Clean Air Act: 1970 to 1990, 1997. Available at: http://www.epa.gov/oar/sect812/. Accessed on 22 January 2007.

55. Dora C, Phillips M, eds. Transport, Environment and Health. Copenhagen: World Health Organization, 2000.

56. Frumkin H. Health, equity, and the built environment. Environ Health Perspect. 2005;113(5):A290-A291.

57. Kjellstrom T, van Kerkhoff L, Bammer G, McMichael T. Comparative assessment of transport risks-how it can contribute to health impact assessment of transport policies. Bull World Health Organ. 2003;81(6):451-457.

58. Miller D. Health-driven environmental issues a top concern in low-GDP countries. Environment Matters, World Bank Annual Review, 2004.

59. ICLEI. Cities for Climate Protection: ICLEI-Local Governments for Sustainability, 2007. Available at: http://www.iclei.org/index.php?id=800. Accessed on 22 January 2007.

60. McMichael AJ. Population health as the 'bottom line' of sustainability: a contemporary challenge for public health researchers. Eur J Public Health. 2006;16(6):579-581. 